\title{
O uso de implantes de compósito bioativo de biocerâmica em matriz polimérica na reconstrução do complexo zigomático orbitário: novas perspectivas em biomateriais
}

\author{
Bioceramic and polymeric bioactive composite implants in orbit zygomatic \\ complex reconstruction: a new prospect for biomaterials
}

\author{
Clarissa Leite Turrer ${ }^{1}$ \\ Ana Rosa Pimentel de Figueiredo ${ }^{2}$ \\ Rodrigo Lambert Oréfice ${ }^{3}$ \\ Pedro Ernani Maciel ${ }^{4}$ \\ Maria Elizabeth Souza da Silveira ${ }^{5}$ \\ Sabrina de Paula Gonçalves ${ }^{6}$ \\ Juliana Senna Figueiredo Barbi ${ }^{7}$
}

\begin{tabular}{|l|}
\hline RESUMO \\
\hline Objetivo: Avaliar o uso de implantes de compósito de matriz polimérica e \\
biocerâmica na reconstrução do complexo zigomático orbitário e seu \\
comportamento através de variáveis clínicas e tomográficas em seis \\
pacientes. Métodos: Foram selecionados seis pacientes portadores de \\
deformidades faciais secundárias a fraturas órbito-zigomáticas graves \\
(n=3) e a seqüelas da radioterapia e enucleação decorrentes do tratamento \\
de retinoblastoma na infância. Este estudo foi submetido a avaliação e \\
aprovação pelo Comitê de Ética em Pesquisa envolvendo seres humanos \\
da Universidade Federal de Minas Gerais, instituição aonde a pesquisa \\
vêm sendo desenvolvida(ETIC203/04). Resultados: Em um ano de acom- \\
panhamento após a implantação do material demonstraram ausência de \\
reações inflamatórias locais. Os achados tomográficos demonstraram bom \\
posicionamento do implante, não ocorrendo migrações ou deslocamentos, \\
ausência de coleções ou reações de partes moles peri-implante e manuten- \\
ção da projeção das partes moles suprajacentes ao implante na região da \\
deformidade preexistente. Conclusão: Os compósitos têm demonstrado \\
bons resultados para areconstituição doesqueleto craniofacial. Obiomaterial \\
utilizado neste estudo alia biocompatibilidade à tecnologia nacional am- \\
pliando as possibilidades da sua utilização a menor custo.
\end{tabular}

Descritores: Cirurgia plástica/reabilitação, implantes orbitários; Materiais biocompatíveis/ uso terapêutico; Próteses e implantes; Ensaio clínico fase I [Tipo de publicação]

\section{INTRODUÇÃ̃O}

Pacientes portadores de cavidades anoftálmicas por causas diversas podem apresentar deformidades que acometem todo terço superior da fa$\mathrm{ce}^{(1)}$ incluindo a região órbito-zigomático-temporal. Aqueles que foram submetidos a tratamento de retinoblastoma unilateral na infância (antes de 1 ano de idade) por meio da enucleação e radioterapia e hoje são adultos (com idade superior a 15 anos) apresentam graves seqüelas em toda a região do complexo zigomático orbitário ipsilateral ${ }^{(2)}$. Estudos demonstram que a radioterapia associada a enucleação podem trazer as piores conseqüências para o terço superior da face relacionadas a retração do conjunto ósseo órbito-zigomático-temporal e da cavidade anoftálmica. Conforme demonstrado em alguns estudos ${ }^{(2-3)}$ a radioterapia, além de exercer efeito deletério 
154 O uso de implantes de compósito bioativo de biocerâmica em matriz polimérica na reconstrução do complexo zigomático orbitário: novas perspectivas em biomateriais

sobre o crescimento ósseo pode provocar atrofia e piora da qualidade do tecidos moles irradiados agravando a deformidade existente.

As características encontradas ao exame físico destes pacientes são freqüentemente: diminuição das dimensões ântero-posteriores e do volume da órbita, deficiência de projeção da eminência zigomática e atrofia de tecidos moles causando deformidade estético-funcional de difícil tratamento ${ }^{(2,4)}$. O aumento da sobrevida e índice de cura desta neoplasia fazem com que questões como qualidade de vida e reabilitação do paciente sejam discutidas. São indivíduos que saem de uma condição grave para a cura, porém com uma seqüela física ${ }^{(2)}$.

Pacientes vítimas de fraturas craniofaciais complexas envolvendo a órbita e o zigomático com perda do globo ocular também apresentam deformidade facial que varia de acordo com a gravidade e intensidade do trauma sofrido. Estes também saem de condições de risco de vida para a cura, porém, com seqüelas importantes. Estas seqüelas são freqüentemente: afundamentos na região órbito-zigomática com perda de projeção, convexidade e contorno ${ }^{(5)}$.

Em ambos os casos (seqüelas de tratamento de tumores com irradiação ou fraturas complexas), o desejo de minimizar a assimetria facial, a possibilidade de reabilitação protética da cavidade anoftálmica e de reparação do terço superior da face levam a procedimentos cirúrgicos em toda unidade facial com tal finalidade. A abordagem destes pacientes deve ser transdisciplinar com vários profissionais atuando simultaneamente, pois, para a obtenção de um resultado satisfatório é necessário cirurgia para reconstruir as paredes orbitárias e o complexo zigomático orbitário maxilar reparando as perdas ósseas que dão projeção aos tecidos moles suprajacentes ${ }^{(1,6)}$.

Intervenções na cavidade para devolução de volume (implantes, enxertos), ampliação de fórnices para melhor adaptação protética e reposicionamento de ligamentos cantais devem ser realizados em seguida, além de procedimentos co-adjuvantes para estímulo ao crescimento facial (no caso de crianças e adolescentes) como ortopedia funcional dos maxilares e ortodontia $^{(4)}$.

O reposicionamento ósseo adequado exerce papel fundamental $^{(1)}$ na melhora da condição da cavidade anoftálmica e está associada a reestruturação da anatomia baseando-se em três princípios fundamentais na seguinte ordem:

- recomposição das paredes ósseas;

- reconstrução dos pilares de sustentação facial;

- devolução de volume à cavidade e procedimentos adjuvantes intracavitários.

Em qualquer caso a realização de apenas um dos princípios é insuficiente na obtenção de resultado satisfatório e inúmeras intervenções na cavidade podem apenas piorar a qualidade dos tecidos, principalmente daqueles que foram irradiados ${ }^{(2,7)}$.

A reconstituição das paredes orbitárias e a reconstrução dos pilares de sustentação facial podem ser realizadas a partir dos seguintes recursos:

- osteotomias de expansão e/ou reposição zigomática com enxertos ósseos autógenos ${ }^{(8)}$ que podem ser retirados das seguin- tes áreas doadoras: crista ilíaca, calota craniana, arcos costais;

- biomateriais como substitutivos ósseos com capacidade de biointegração ao sítio receptor.

A vantagem do enxerto autógeno é a compatibilidade biológica tecidual, porém com o tempo há certa absorção do enxerto e conseqüente perda de resultado ${ }^{(9)}$. A desvantagem está relacionada a áreas doadoras de enxerto e aumento da morbidade do ato cirúrgico (maior tempo de cirurgia e exposição de outro campo operatório) ${ }^{(10)}$. Apesar de técnicas descritas com o uso de enxertos autógenos como suporte de osteotomias para minimizar o efeito de absorção do mesmo, a questão da área doadora e quantidade de tecido disponível ainda permanece como desvantagem desta técnica ${ }^{(2)}$.

Os biomateriais encontram a maior vantagem na facilidade técnica do seu emprego, eliminando a necessidade de área doadora, podem ser adquiridos na forma e quantidade necessária ao contorno desejado, ou podem ser trabalhados durante a cirurgia permitindo melhor adaptação ao sítio receptor.

Existem materiais porosos (polímeros e biocerâmicas) indicados para a reconstrução do esqueleto crânio facial com estas propriedades ${ }^{(10-11)}$. O osso autógeno não apresenta esta maleabilidade necessária a adaptação ao sítio receptor ${ }^{(12)}$. Atualmente, existem materiais disponíveis em comercialização que podem ser usados para reparação do esqueleto facial com boa integração e biocompatibilidade ${ }^{(13-14)}$. Entre eles destacase o polietileno poroso de alta densidade, registrado como Medpor $^{\circledR}$, manufaturado pela Porex, EUA. Este material é bastante utilizado na prática há mais de dez anos e têm se destacado pela excelente biointegração tecidual já demonstrada por inúmeros estudos ${ }^{(13-16)}$.

A grande desvantagem destes biomateriais é o custo ainda muito elevado por se tratar de material não manufaturado no Brasil, o que faz com que estudos nesta área de conhecimento sejam cada vez mais estimulados deixando os laboratórios e seguindo as etapas de investigação científica necessárias ${ }^{(17)}$.

A busca constante pela melhor biointegração de biomateriais estimula estudos e atualmente têm surgido um grupo de materiais chamados de compósitos ${ }^{(18-19)}$, cuja principal característica é a associação de dois ou mais componentes com propriedades diferentes como resistência, tenacidade e capacidade de moldar para melhor adaptação ao sítio receptor. Os componentes diferentes podem ser identificados no material e não perdem suas propriedades individuais. A associação de polímeros com cerâmicas tem demonstrado eficácia melhorando a biointegração e a resistência do polímero puro. O biomaterial utilizado neste estudo é um compósito constituído por uma matriz polimérica de polietileno poroso associada a biocerâmica (biovidro) na proporção de $10 \%$ que foi submetido a ensaio experimental comparativo. Este estudo apresentou resultados favoráveis ressaltando a formação de interface entre implante e hospedeiro com menor índice de células inflamatórias comparando-o ao controle padrão ouro (Medpor $\left.{ }^{\circledR}\right)^{(17)}$. Esta propriedade foi considerada importante vantagem deste compósito em relação ao controle além de permitir a continua- 
ção da investigação científica deste material valorizando a pesquisa em biomateriais produzidos em âmbito nacional e de custo menor.

\section{OBJETIVO}

O presente estudo tem o objetivo de avaliar o comportamento do implante de compósito de biocerâmica em matriz polimérica a $10 \%$ utilizado na reconstrução da órbita por meio de variáveis clínicas e de imagem (tomografia computadorizada) no acompanhamento pós-operatório de seis pacientes.

\section{MÉTODOS}

Este é o primeiro estudo com a utilização deste material em pacientes após a aprovação e publicação de estudos experimentais in vivo e está aprovado e autorizado pelo Comitê de Ética e Pesquisa em Seres humanos (COEP) da Universidade Federal de Minas Gerais (ETIC203/04).

Foram selecionados para o estudo seis pacientes com idade entre 15 e 50 anos, que apresentavam seqüelas de fraturas orbitárias complexas (com mais de 1 ano de evolução) ou seqüelas da enucleação seguida de radioterapia no tratamento de retinoblastoma antes de 1 ano de idade, com condição de comparecer às revisões periódicas, capacidade mental normal, presença de deformidade na região zigomático orbitária identificada por exame físico e tomografia computadorizada e desejo expresso em melhorar o problema existente (Quadro 1). Os pacientes receberam orientações sobre o estudo e foram orientados a ler e assinar termo de consentimento livre e esclarecido.

Os implantes foram produzidos no Laboratório de Biomateriais do Depto de Engenharia Metalúrgica e de Materiais da Escola de Engenharia da Universidade Federal de Minas Gerais a partir de modelagem individual realizada no paciente.

Foram selecionados seis pacientes com órbitas anoftálmicas e deformidades na região órbito-zigomático-temporal: 3 pacientes submetidos a enucleação por retinoblastoma na infância (antes de 1 ano) seguida de radioterapia e 3 pacientes vítimas de acidentes automobilísticos com fraturas faciais acometendo o terço superior da face e que evoluíram com perda do globo ocular por ocasião do traumatismo.

Após anamnese, exame físico e registro de informações relacionadas ao aspecto da deformidade existente, os pacien- tes foram submetidos a tomografia computadorizada da face com reconstrução tridimensional o que permitiu melhor avaliação da deformidade e facilitou o planejamento cirúrgico. A condição cavidade anoftálmica foi apresentada ao Comitê de Ètica e autorizada, por se tratar de estudo fase I e não se conhecer as possibilidades de desfecho, evitando o comprometimento do olho em caso de desfecho desfavorável.

Os procedimentos cirúrgicos e anestésicos seguiram padrões já estabelecidos e realizados na Instituição (Hospital São Geraldo, anexo Hospital das Clínicas, Universidade Federal de Minas Gerais).

A técnica cirúrgica utilizada foi abordagem subciliar subperiosteal para exposição do defeito em região zigomática e parede lateral da órbita inferior e incisão coronal unilateral para melhor exposição da parede lateral e do rebordo superior além de descolamento de retalho de pericrânio para cobrir o implante. Esta técnica cirúrgica, descrita em estudo prévio para este tipo de reconstrução, foi utilizada com o objetivo de melhorar a condição de vascularização no sítio operatório, além de aumentar a projeção de tecidos moles suprajacentes ao $\operatorname{osso}^{(7)}$.

Os achados cirúrgicos corresponderam às características clínicas encontradas e os pacientes apresentavam falta de projeção da região zigomática e deficiências das dimensões ântero-posteriores da órbita. Os implantes foram posicionados nas regiões aonde havia necessidade de preenchimento para melhorar a projeção de tecidos moles suprajacentes ao mesmo. Em todos os pacientes houve necessidade de ajustar o implante para melhor adaptação ao sítio receptor. Este ajuste foi realizado com o próprio bisturi (lâmina 15) pois este material permite este manuseio, além da facilidade de perfuração do implante para fixação e estabilização do mesmo com fios de aço (aciflex 0) ou parafusos bicorticais de titânio (sistema 2,0 mm, MDT ${ }^{\circledR}$, Brasil). O retalho de pericrânio foi utilizado para cobertura dos implantes com o objetivo de melhorar a vascularização local principalmente nos casos que sofreram radiação. Em um caso (paciente 4) não houve possibilidade deste recurso pois o paciente, vítima de trauma craniofacial complexo, havia sido submetido previamente na ocasião do tratamento primário a craniotomia descompressiva por acesso bicoronal inviabilizando o uso deste retalho nesta intervenção.

As intervenções cirúrgicas ocorreram sem quaisquer intercorrências e a média de permanência hospitalar foi 48 a 72

Quadro 1. Descrição dos pacientes do estudo de acordo com idade, sexo, causa da deformidade, número de implantes utilizados e tempo de acompanhamento pós-operatório

\begin{tabular}{|c|c|c|c|c|c|}
\hline Paciente & Idade (anos) & Sexo & Diagnóstico (causa da deformidade) & Implantes (N) & Acompanhamento (meses) \\
\hline (1) C.C & 15 & M & Retinoblastoma (enucleação e radioterapia) & 2 & 18 \\
\hline (2) L.A.R & 17 & $\mathrm{~F}$ & Retinoblastoma (enucleação e radioterapia) & 2 & 11 \\
\hline (3) F.R & 18 & $\mathrm{~F}$ & Retinoblastoma (enucleação e radioterapia) & 2 & 10 \\
\hline (4) W.S.R & 23 & M & Seqüela de fratura de órbita & 2 & 17 \\
\hline (5) F.A.C & 34 & $\mathrm{~F}$ & Seqüela de fratura de órbita & 1 & 12 \\
\hline (6) E.F & 50 & M & Seqüela de fratura de órbita & 1 & 14 \\
\hline
\end{tabular}


156 O uso de implantes de compósito bioativo de biocerâmica em matriz polimérica na reconstrução do complexo zigomático orbitário: novas perspectivas em biomateriais

horas. Foram realizadas seis cirurgias e implantadas 10 peças nos seis pacientes do estudo. Os locais de fixação dos implantes foram: parede lateral e anterior da órbita e região zigomática anterior (corpo do osso zigomático até a primeira porção do arco zigomático). A média de tamanho dos implantes foi: $39 \mathrm{~mm}$ (comprimento) x 16,4 mm (largura) x 4,7 mm (altura).

Os pacientes foram acompanhados no pós-operatório em revisões semanais no primeiro mês e quinzenais até o terceiro mês. Após três meses as revisões foram mensais até completar 12 meses de acompanhamento e depois trimestrais até o momento (24 meses). Durante as revisões as seguintes variáveis foram investigadas sempre pelo mesmo profissional: presença de edema, hiperemia, dor (se o paciente estava em uso de analgésico ou não), secreções em ferida operatória, exposição do implante e/ou necessidade de remoção do mesmo. Em caso de retirada de qualquer implante o mesmo seria submetido a exame histopatológico e análise histomorfométrica. As tomografias computadorizadas foram realizadas após um ano de controle e foram comparadas com os mesmos cortes do préoperatório. Foram avaliadas as seguintes variáveis: posição do implante, ocorrência de migração, presença de coleção ou reação inflamatória evidenciada ao exame de imagem e obtenção de projeção de partes moles na região zigomática.

\section{RESULTADOS}

Durante as revisões ambulatoriais, o edema esteve presente em todos os casos apresentando regressão completa entre a terceira e quarta revisão $\left(20^{\circ}\right.$ e $30^{\circ}$ dia de pós-operatório) se restringindo ao sítio operatório. Hiperemia esteve presente em 1 caso (paciente 2) com regressão completa em 15 dias. A dor foi considerada se o paciente estava fazendo uso de analgésico e observamos esta variável em 1 caso (paciente 2) com melhora em 15 dias. À palpação, os implantes encontravam-se bem posicionados, fixos e sem sinais locais indicativos de processo inflamatório. No paciente que não foi utilizado o retalho de pericrânio no revestimento do implante observou-se escassez de tecidos moles devido também a presença de fibrose e cicatrizes conseqüentes ao trauma em toda região periorbitária.

Obteve-se melhora importante do contorno e da projeção do conjunto órbito-zigomático em todos os casos, documentada através de tomografia computadorizada que evidenciou os implantes posicionados subjacentes aos tecidos moles projetados. A tomografia computadorizada não evidenciou quaisquer coleções e/ou reação tecidual ao redor dos implantes corroborando o exame clínico durante as revisões (Figura 1: A, B, C, D, E, F).

Não houve nenhum caso de infecção, nem extrusão de implantes. Todos os pacientes foram submetidos a intervenções intracavitárias no período de revisões ambulatoriais, com objetivo de melhorar a condição da cavidade anoftálmica para reabilitação protética. Nenhum destes procedimentos interferiu ou provocou qualquer reação na região dos implantes. Não foram observadas secreções em ferida cirúrgica e nem quais- quer outras intercorrências relacionadas a exposição de implante associada ou não a necessidade de remoção do mesmo.

O período de acompanhamento pós-operatório até o momento é de 20 meses.

A osteossíntese na região fronto zigomática não foi suficiente para o tratamento de todo complexo zigomático orbitário e o afundamento da região malar bem como a perda de projeção dos tecidos moles nesta região ainda estavam presentes ao exame clínico e de tomografia computadorizada, ressaltando a gravidade da seqüela neste caso (Figura 2: A, B, C, $\mathrm{D}, \mathrm{E})$.

O pós-operatório evoluiu sem quaisquer intercorrências e a tomografia computadorizada de controle, após um ano de acompanhamento, evidencia o ganho de projeção anterior minimizando o aspecto de afundamento e assimetria na região afetada pelo trauma (Figura 2: F, G). Os achados tomográficos demonstraram que os implantes permaneceram bem posicionados no sítio de implantação apresentando bom desempenho na projeção de partes moles.

\section{DISCUSS ÃO}

O tratamento das deformidades faciais fazem parte da experiência clínica diária do cirurgião plástico. Quando ocorre comprometimento do contorno orbitário associado a condição de perda do globo ocular por tumor ou por causa acidental nos deparamos com uma deformidade de resolução complexa que exige conhecimento profundo da anatomia local, da fisiopatologia do trauma e da abordagem transdisciplinar que é necessária na obtenção de resultados melhores ${ }^{(7)}$.

A cirurgia reparadora na órbita tem como princípio fundamental a recomposição (reorganização) das estruturas anatômicas afetadas pela lesão ${ }^{(1)}$. A cirurgia da face com este objetivo prioriza a reconstrução dos pilares de sustentação facial e dos contornos particulares do esqueleto facial que devolvem à face a harmonia e simetria, principalmente quando a hemiface contralateral não foi acometida.

A abordagem cirúrgica envolve múltiplas etapas e deve priorizar o reposicionamento e a devolução do contorno da órbita e posteriormente realizar as intervenções intracavitárias com objetivos de recuperação de volume e reabilitação ${ }^{(2,4)}$. A perda do globo ocular ressalta a deformidade, piora a condição da órbita e pode ser considerada como fator de pior prognóstico em relação à qualidade estética do resultado ${ }^{(4)}$. Nestes pacientes a reabilitação torna-se processo mais complexo, envolvendo abordagens mais amplas em todo complexo zigomático orbitário maxilar e não apenas intervenções múltiplas localizadas na cavidade que pouco contribuirão se não houver uma visão terapêutica mais abrangente e transdisciplinar ${ }^{(7)}$.

Existem muitas técnicas cirúrgicas descritas e a necessidade de enxertos ósseos autógenos ou biomateriais com o objetivo de recompor tecido ósseo sempre está presente nas discussões. O enxerto ósseo autógeno considerado padrão ouro em relação a biocompatibilidade e custo apresenta como des- 
O uso de implantes de compósito bioativo de biocerâmica em matriz polimérica na reconstrução do complexo zigomático orbitário:

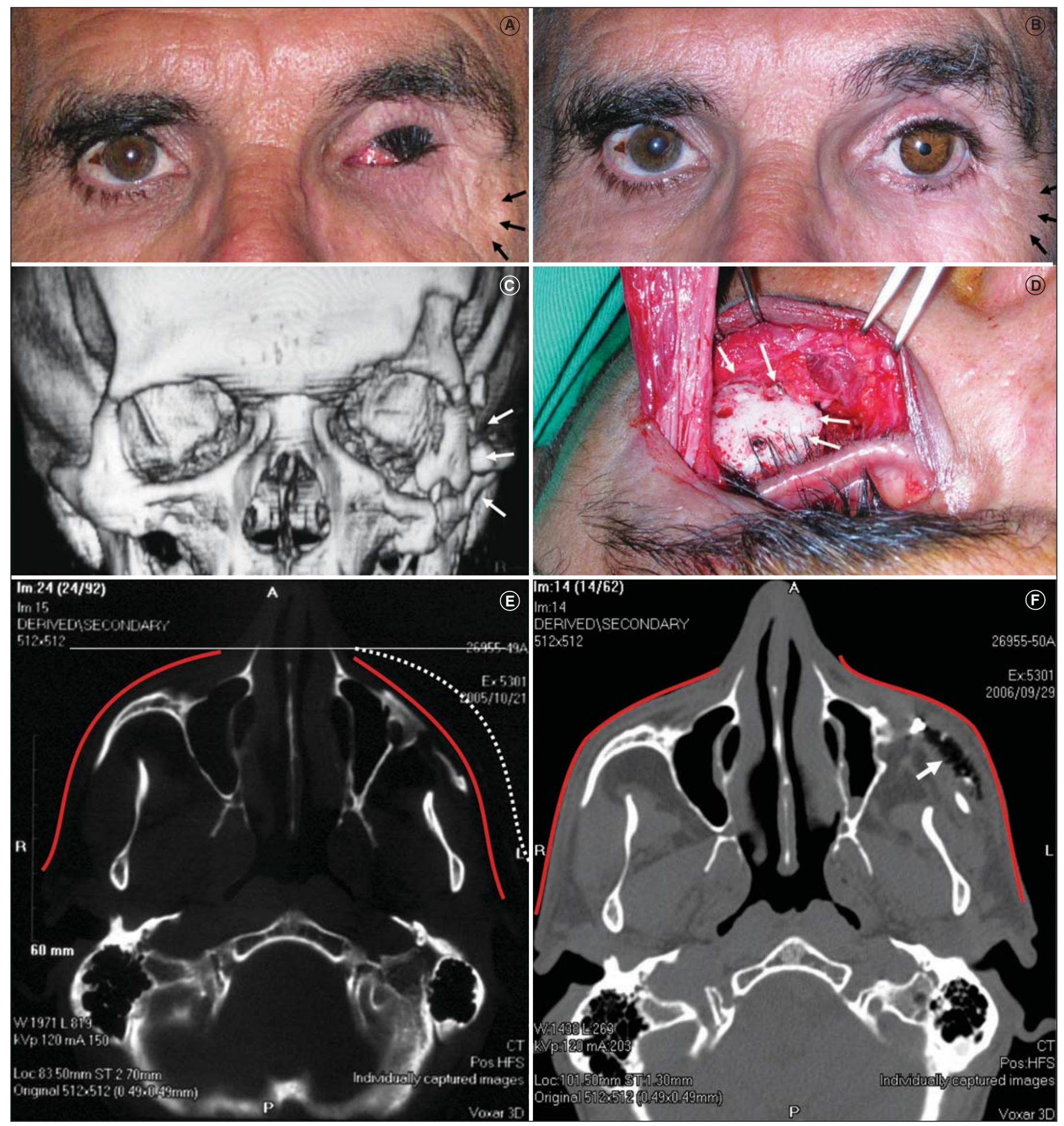

Figura 1 - A: paciente 6 apresentando seqüela de fratura zigomático orbitária grave com perda do globo ocular à esquerda (vista anterior). Observase cavidade anoftálmica e afundamento da parede orbitária lateral e da eminência zigomática com perda da projeção de partes moles (setas); B: pós-operatório (vista anterior): revisão de ano, após reconstituição do processo zigomático orbitário com implante de compósito de biocerâmica em matriz polimérica e reabilitação protética ocular. Observa-se a devolução do contorno lateral da órbita e da projeção malar (setas); C: imagem pré-operatória de tomografia computadorizada com reconstrução tridimensional demonstrando grave cominução em todo bloco zigomático orbitário esquerdo (setas); D: imagem de ato operatório. Observa-se o implante posicionado na região do corpo do zigomático por acesso subciliar subperiosteal sendo recoberto por um retalho de pericrânio. Fixação rígida com parafusos de titânio (setas); E: imagem pré-operatória de tomografia computadorizada em corte axial evidenciando perda de projeção anterior na região do corpo do osso zigomático esquerdo (em vermelho). A linha tracejada demonstra a projeção desejada, simétrica à mesma região contralateral; F: imagem pós-operatória de tomografia computadorizada em corte axial (mesmo corte da imagem anterior) demonstrando o avanço obtido de partes moles à esquerda e a projeção anterior semelhante ao lado direito (em vermelho). $O$ implante é evidenciado com imagem radiolúcida devido a sua porosidade (seta). Os meios de fixação são radiopacos. 
158 O uso de implantes de compósito bioativo de biocerâmica em matriz polimérica na reconstrução do complexo zigomático orbitário: novas perspectivas em biomateriais
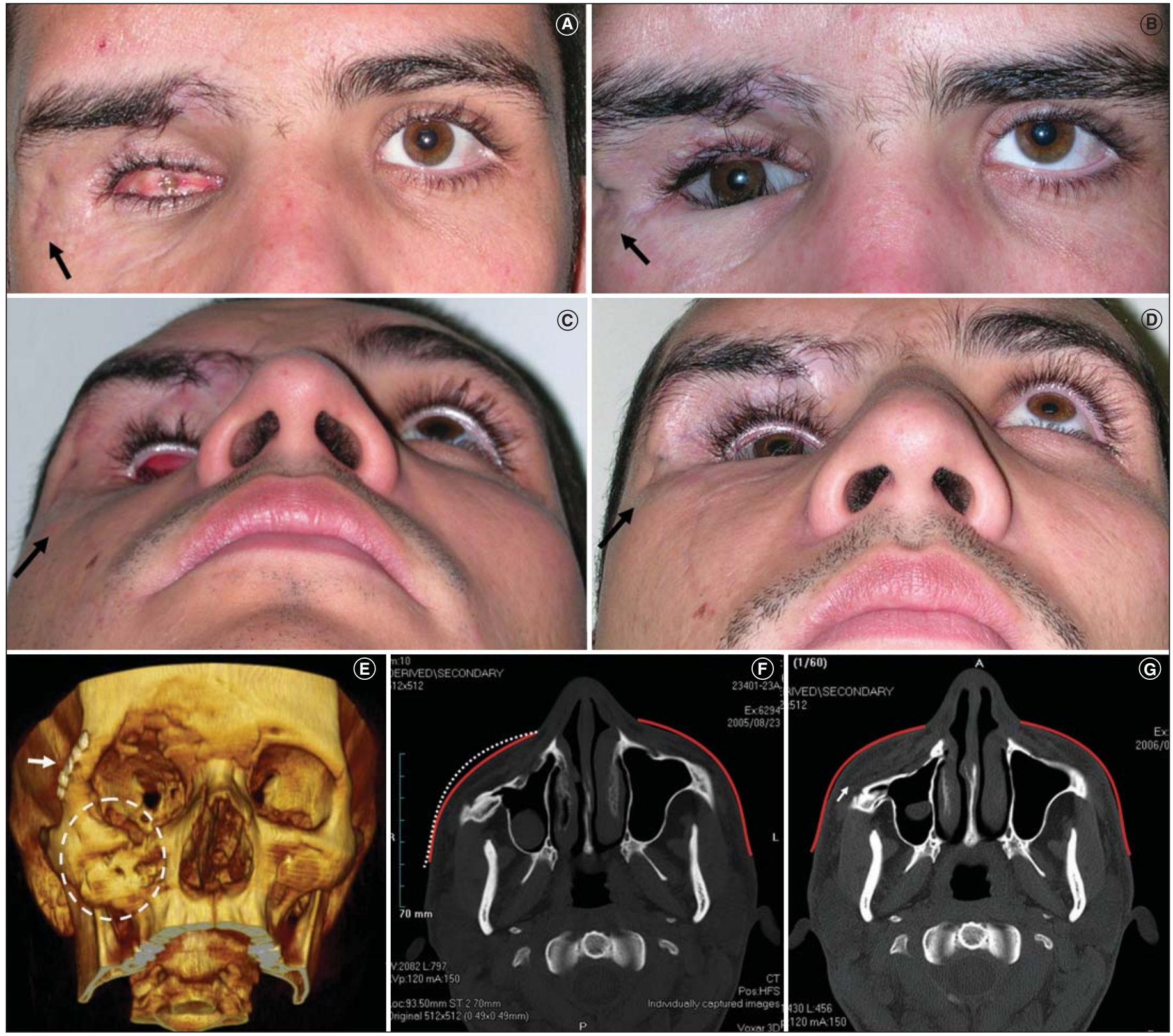

Figura 2 - A: paciente 4 apresentando seqüela de fratura zigomático orbitária grave com perda do globo ocular à direita (vista anterior), afundamento malar e presença de cicatrizes e retrações na região palpebral e periorbitária (seta); B: pós-operatório (vista anterior) - revisão de 1 ano. A presença de cicatrizes inestéticas e retraídas na região periorbitária dificultam o reposicionamento de ligamentos cantais e a melhora da hipotopia (seta); C: pré-operatório (vista inferior) demonstrando o afundamento da região malar e a falta de projeção de tecidos moles (seta); D: pós-operatório (vista inferior) - revisão de 1 ano. Observa-se devolução no contorno da região malar (seta); E: imagem pré-operatória de tomografia computadorizada com reconstrução tridimensional. Este paciente foi submetido a osteossíntese única primária da fratura zigomático orbitária (seta) e ainda apresentava afundamento da parede lateral da órbita e de todo complexo zigomático (círculo); F: imagem pré-operatória de tomografia computadorizada em corte axial evidenciando perda de projeção anterior na região do corpo do osso zigomático direito (em vermelho). A linha tracejada demonstra a projeção desejada simétrica à mesma região contralateral; G: imagem pós-operatória de tomografia computadorizada em corte axial (mesmo corte da imagem anterior) demonstrando o avanço obtido de partes moles à direita e a projeção anterior semelhante ao lado esquerdo (em vermelho). 0 implante é evidenciado com imagem radiolúcida devido a sua porosidade (seta). Os meios de fixação são radiopacos.

vantagem a necessidade de área doadora que aumenta a morbidade do ato operatório, além de perda de resultado relacionada a absorção do mesmo já demonstrada em estudos anteriores $^{(8-9)}$. Outro fator é que o osso não apresenta a maleabilidade necessária a adaptação ao sítio receptor principalmente em regiões como paredes orbitárias e região zigomática aonde uma certa convexidade do implante ou enxerto se faz necessária para um resultado mais estético e simétrico ${ }^{(20)}$. Alguns autores referem a dificuldade de adaptação de enxertos ósseos a sítios receptores da face pois o esqueleto facial apresenta curvas que não podem ser reproduzidas no enxerto devido a pouca plasticidade óssea e buscam materiais que podem ser 
moldados e trabalhados durante a cirurgia permitindo melhor adaptação e conseqüentemente melhor resultado estético ${ }^{(21)}$.

Os materiais disponíveis e comercializados atualmente para este fim, destacando-se o polietileno poroso de alta densida$\mathrm{de}^{(22)}$, registrado como Medpor ${ }^{\circledR}$, fabricado pela Porex, EUA, apresentam custo elevado, impossibilitando o acesso amplo a este recurso, além de apresentarem complicações associadas a fenômenos de rejeição e reações inflamatórias ${ }^{(23)}$.

A biocompatibilidade dos materiais utilizados na área médica vem sendo amplamente estudada e muitas publicações sobre o tema demonstram a constante preocupação dos pesquisadores em encontrar soluções para melhorar os fenômenos de biointegração de um material minimizando o impacto das reações inflamatórias locais e sistêmicas ${ }^{(19,24-25)}$. As propriedades e apresentações de materiais também têm sido muito discutidas, pois atualmente o termo biocompatibilidade é bem abrangente e envolve desde fenômenos físico-químicos celulares que ocorrem a nível de superfície dos materiais até fenômenos mecânicos que avaliam estrutura microscópica do implante, sua capacidade de absorver impacto, sua resistência e tenacida$\mathrm{de}^{(26-27)}$. O conhecimento das propriedades particulares dos materiais e sua indicação em determinado local são fatores determinantes no êxito da cirurgia e na utilização do biomaterial sob a forma de implante como órtese ou prótese ${ }^{(28-29)}$.

O presente estudo analisa através de variáveis clínicas e estudos de imagem o comportamento e a biocompatibilidade de um compósito bioativo já submetido a testes in vitro e experimentais comparativos com resultados satisfatórios nos modelos estudados. O componente polimérico (polietileno poroso) apresenta características muito apropriadas para o objetivo proposto: reconstrução de complexo zigomático orbitário, pois sua capacidade de moldar permite fácil manuseio intraoperatório permitindo adaptação a paredes da órbita e eminência zigomática além da colonização do implante por fibroblastos que migram para o interior dos poros aumentando a integração do material. O componente cerâmico provoca a deposição de hidroxiapatita carbonatada na superfície do implante o que atrai fibras colágenas, mucopolissacárides e glicoproteínas formando uma interface orgânica-inorgânica favorecendo a adesão do implante à superfície receptora. Esta característica foi considerada, em estudo experimental prévio, vantagem em relação ao implante de Medpor $^{\circledR}$ - padrão ouro, pois diferenças entre a composição celular da interface demonstraram um padrão menos inflamatório no compósito ${ }^{(17)}$. Compósitos de biocerâmica em matriz polimérica foram utilizados em cirurgias de reconstrução orbitária com resultados favoráveis relacionados a biocompatibilidade e a propriedades dos materiais, conforme demonstrado no estudo de Downes et al. ${ }^{(30)}$.

Este compósito encontrou na reconstrução do esqueleto facial excelente indicação principalmente pela facilidade técnica de manuseio e adaptação a convexidade do esqueleto facial. Inúmeros autores já demonstraram em estudos prévios preocupação com esta propriedade de determinado material no local a ser implantado ${ }^{(28,31-32)}$.
As variáveis clínicas como edema, hiperemia e dor no pósoperatório ocorreram em todos os casos regredindo entre o $15^{\circ}$ e $30^{\circ}$ dia de pós-operatório sem quaisquer intercorrências, apresentando evolução esperada de qualquer pós-operatório de cirurgia da face. As variáveis específicas relacionadas a fenômenos de rejeição do material ${ }^{(14)}$, como secreções ou exposição do implante não foram observadas neste grupo de pacientes.

A reconstituição da parede da órbita apresenta como peculiaridade a necessidade de se reproduzir no implante os contornos necessários à adaptação do mesmo ao sítio receptor.

Apesar do implante ser individualizado e ter sido usinado a partir de molde individual para cada paciente ainda assim, no intra-operatório alguns ajustes são necessários para melhor adaptação e contato com a superfície óssea do sítio receptor. Esta propriedade denominada trabalhabilidade ${ }^{(17)}$, que traduz capacidade técnica de esculpir e moldar o implante deve ser observada e ressaltada como fundamental em implantes faciais $^{(21,32)}$. Neste aspecto, os implantes cerâmicos apesar da sua alta biocompatibilidade apresentam desvantagem, pois são muito rígidos com pouca plasticidade e mesmo sendo usinados sob medida a partir de prototipagem as perfurações para sua fixação podem produzir rachaduras microscópicas devido a baixa tenacidade das cerâmicas e comprometer a estrutura do mesmo contribuindo para o insucesso deste tipo de implante ${ }^{(31)}$

Os implantes de polímeros porosos apresentam alta plasticidade, propriedade particular deste grupo, que permite esculpir, moldar e perfurar sem comprometer a estrutura do implante porém estes materiais possuem menor resistência a carregamento mecânico não devendo ser utilizados em áreas de esforço contínuo ${ }^{(33)}$. Na região órbito-zigomática encontram boa indicação, pois o objetivo é devolver contorno e projeção, não havendo ação muscular intensa no local ${ }^{(34)}$.

Nos casos estudados não ocorreu nenhum tipo de reação inflamatória clínica que sugerisse rejeição aos implantes. Alguns estudos utilizam a tomografia para avaliação quantitativa da deformidade, permitindo melhor planejamento cirúrgico e comparação com resultados pós-operatórios em relação aos ganhos na projeção de partes moles ${ }^{(35-36)}$. A tomografia computadorizada, exame de imagem de escolha para avaliação comparativa de resultados obtidos devido sua acurácia e reprodutibilidade ${ }^{(35-36)}$ demonstrou boa qualidade dos tecidos locais em torno do implante sem nenhum tipo de coleção ou outros sinais evidentes de reação local observando se também nos casos operados, melhora da projeção anterior na região da eminência zigomática minimizando a assimetria prévia. Os pacientes operados serão acompanhados regularmente por período de tempo maior, mas os desfechos obtidos até o momento têm sido favoráveis e encorajadores para a continuação das etapas de investigação científica deste novo biomaterial.

Conforme ilustrado, os casos apresentavam seqüelas graves aonde a abordagem interdisciplinar é fundamental para o êxito da cirurgia restauradora dos contornos órbito-zigomá- 
160 O uso de implantes de compósito bioativo de biocerâmica em matriz polimérica na reconstrução do complexo zigomático orbitário: novas perspectivas em biomateriais

ticos e tomografia computadorizada com reconstrução tridimensional é importante recurso no planejamento da cirurgia.

\section{CONCLUSÃO}

Pesquisas e estudos com biomateriais têm sido desenvolvidos com o objetivo de substituição de materiais biológicos autógenos na reparação de perdas teciduais. O desenvolvimento de conceitos como biocompatibilidade, biointegração e compósitos têm trazido enorme contribuição para este campo de estudo. Este estudo apresenta resultados encorajadores e nos autoriza junto ao Comitê de Ética a prosseguirmos para uma série maior de pacientes para análise de outras variáveis abrindo novas perspectivas em biomateriais produzidos com tecnologia nacional a custos menores, ampliando o acesso a este recurso.

\section{ABSTRACT}

Purpose: To evaluate through clinical and tomographic parameters implant behavior in orbital zygomatic reconstruction in six patients. Methods: The subjects for this preliminary study consisted of six anophthalmic socket patients (3 patients presented residual orbital zygomatic deformities after complex facial fractures and 3 patients presented orbital zygomatic retraction after enucleation and radiotherapy to treat retinoblastoma in infancy). These deformities were surgically corrected with this composite implant. This study was approved and authorized by the Universidade Federal de Minas Gerais Ethical Committee for Research in Human Subjects (ETIC 203/04). Clinical data and tomographic images were utilized to assess the outcome of this study. Results: There were no complications and tomographic findings revealed no implant reactions or migration and a good maintenance of soft tissue projection in the operated areas was achieved. Success of outcome in this preliminary study were encouraging. Conclusion: This study will be continued enrolling a larger sample and longer follow-up. Composite biomaterials have presented a good outcome in facial reconstructive surgery. The composite implants in this group have a good biocompatibility and combined with national technology can reduce costs providing more possibilities to many more patients.

Keywords: Surgery, plastic/rehabilitation, orbital implants; Biocompatible materials/therapeutic use; Protheses and implants; Clinical trial, phase I [Publication type]

\section{REFERÊNCIAS}

1. Spinelli HM, Forman DL. Current treatment of post-traumatic deformities. Residual orbital, adnexal, and soft-tissue abnormalities. Clin Plast Surg. 1997;24(3):519-30.

2. Jackson IT, Carls F, Bush K, Topf J, Xiao H, Gowda M, Audet B. Assess- ment and treatment of facial deformity resulting from radiation to the orbital area in childhood. Plast Reconstr Surg. 1996;98(7):1169-79; discussion 1180-1.

3. Messmer EP, Fritze H, Mohr C, Heinrich T, Sauerwein W, Havers W, et al Long-term treatment effects in patients with bilateral retinoblastoma: ocular and mid-facial findings. Graefes Arch Clin Exp Ophthalmol. 1991;229(4):309-14.

4. Clauser L, Sarti E, Dallera V, Galiè M. Integrated reconstructive strategies for treating the anophthalmic orbit. J Craniomaxillofac Surg. 2004;32(5):279-90.

5. Manfredi SJ, Raji MR, Sprinkle PM, Weinstein GW, Minardi LM, Swanson TJ. Computerized tomographic scan findings in facial fractures associated with blindness. Plast Reconstr Surg. 1991;68(4):479-90.

6. Ainbinder DJ, Haik BG, Mazzoli RA. Anophthalmic socket and orbital implants. Role of CT and MR imaging. Radiol Clin North Am. 1998;36(6): 1133-47; xi.

7. Krastinova D, Mihaylova M, Kelly MB. Surgical management of the anophthalmic orbit, part 2: post-tumoral. Plast Reconstr Surg. 2001;108(4):827-37.

8. Tessier P. Autogenous bone grafts taken from the calvarium for facial and cranial applications. Clin Plast Surg. 1982;9(4):531-8.

9. Manson PN. Facial bone healing and bone grafts. A review of clinical physiology. Clin Plast Surg. 1994;21(3):331-48.

10. Potter JK, Ellis E. Biomaterials for reconstruction of the internal orbit. J Oral Maxillofac Surg. 2004;62(10):1280-97.

11. Gosain AK, Persing JA. Biomaterials in the face: benefits and risks. J Craniofac Surg. 1999;10(5):404-14.

12. Salyer KE, Hall CD. Porous hydroxyapatite as an onlay bone-graft substitute for maxillofacial surgery. Plast Reconstr Surg. 1989;84(2):236-44.

13. Rubin JP, Yaremchuk MJ. Complications and toxicities of implantable biomaterials used in facial reconstructive and aesthetic surgery: a comprehensive review of the literature. Plast Reconstr Surg. 1997; 100(5):1336-53. Comment in: Plast Reconstr Surg. 1998;102(5):1766-8.

14. Wellisz T, Kanel G, Anooshian RV. Characteristics of the tissue response to Medpor porous polyethylene implants in the human facial skeleton: the longterm effects of biomedical implants. J Long Term Eff Med Implants. 1993; 3(3):223-35.

15. Romano JJ, Iliff NT, Manson PN. Use of Medpor porous polyethylene implants in 140 patients with facial fractures. J Craniofac Surg. 1993;4(3):142-7.

16. Choi JC, Sims CD, Casanova R, Shore JW, Yaremchuk MJ. Porous polyethylene implant for orbital wall reconstruction. J Craniomaxillofac Trauma. 1995;1(3):42-9

17. França VP, Figueiredo ARP, Vasconcelos AC, Oréfice RL. Estudo comparativo experimental de compósito bioativo de matriz polimérica para aplicação em cirurgia plástica ocular na substituição tecidual. Arq Bras Oftalmol. 2005; 68(4):425-31.

18. Wang M. Developing bioactive composite materials for tissue replacement Biomaterials. 2003;24(13):2133-51.

19. Rea SM, Brooks RA, Schneider A, Best SM, Bonfield W. Osteoblast-like cell response to bioactive composites-surface-topography and composítion effects. J Biomed Mater Res B Appl Biomater. 2004;70(2):250-61.

20. Whitaker LA. Aesthetic augmentation of the malar-midface structures. Plast Reconstr Surg. 1987;80(3):337-46.

21. Steinsapir KD. Aesthetic and restorative midface lifting with hand-carved, expanded polytetrafluoroethylene orbital rim implants. Plast Reconstr Surg. 2003;111(5):1727-37; discussion 1738-41.

22.Yaremchuk MJ. Facial skeletal reconstruction using porous polyethylene implants. Plast Reconstr Surg. 2003;111(6):1818-27.

23. Sclafani AP, Romo T $3^{\text {rd }}$, Silver L. Clinical and histologic behavior of exposed porous high-density polyethylene implants. Plast Reconstr Surg. 1997;99(1):41-50.

24. Wellisz T, Lawrence M, Jazayeri MA, Golshani S, Zhou ZY. The effects of alloplastic implant onlays on bone in the rabbit mandible. Plast Reconstr Surg. 1995;96(4):957-63.

25. Rubin PA, Popham JK, Bilyk JR, Shore JW. Comparison of fibrovascular ingrowth into hydroxyapatite and porous polyethylene orbital implants. Ophthal Plast Reconstr Surg. 1994;10(2):96-103.

26. Choi JC, Bstandig S, Iwamoto MA, Rubin PA, Shore JW. Porous polyethylene sheet implant with a barrier surface: a rabbit study. Ophthal Plast Reconstr Surg. 1998;14(1):32-6.

27. Rubin PA, Bilyk JR, Shore JW. Orbital reconstruction using porous polyethylene sheets. Ophthalmology. 1994;101(10):1697-708.

28. Eppley BL, Sadove AM, German RZ. Evaluation of HTR polymer as a craniomaxillofacial graft material. Plast Reconstr Surg. 1990;86(6):1085-92.

29. Golshani S, Zhou ZY, Gade P. Applications of Medpor porous polyethylene in facial bone augmentation. Am J Cosmet Surg. 1994;11(2):105-9. 
30. Downes RN, Vardy S, Tanner KE, Bonfield W. Hydroxyapatite - polyethylene composite in orbital surgery. Bioceramics. 1991;4:239-46.

31. Dusková M, Kozák JI, Mazánek JI, Smahel ZK, Vohradník M. Bioceramics as an option in correction of facial skeleton deformities. J Craniofac Surg. 2000;11(5):470-9.

32. Taub PJ, Rudkin GH, Clearihue WJ $3^{\text {rd }}$, Miller TA. Prefabricated alloplastic implants for cranial defects. Plast Reconstr Surg. 2003;111(3):1233-40.

33. Purdy EP. Oculoplastic and orbital applications of porous high-density polyethylene implants. Curr Opin Ophthalmol. 1997;8(5):57-63.
34. Yaremchuk MJ. Infraorbital rim augmentation. Plast Reconstr Surg. 2001; 107(6):1585-92; discussion 1593-5.

35. Manson PN, Grivas A, Rosenbaum A, Vannier M, Zinreich J, Iliff N. Studies on enophthalmos: II. The measurement of orbital injuries and their treatment by quantitative computed tomography. Plast Reconstr Surg. 1986;77(2):203-14.

36. Waitzman AA, Posnick JC, Armstrong DC, Pron GE. Craniofacial skeletal measurements based on computed tomography: Part I. Accuracy and reproducibility. Cleft Palate Craniofac J. 1992;29(2):112-7. Comment in: Cleft Palate Craniofac J. 1992;29(5):489. 